\title{
IMPROVEMENT OF CEMENT PASTES COMPOSITE PROPERTIES CONTAINING CLAY NANOPARTICLES
}

\author{
${ }^{*}$ MOHAMED HEIKAL*, **, IVON M. HELMY***, SHEREEN AWAD****, NOHA S. IBRAHIM***, **** \\ *Chemistry Department, Faculty of Science, Benha University, Benha, Egypt \\ **Chemistry Department, College of Science, Imam Mohammad Ibn Saud Islamic University (IMSIU), \\ P.O Box 90950, Rivadh 11623, Saudi Arabia \\ ***Chemistry Department, Faculty of Science, Zagazig University, Zagazig, Egypt \\ ****Faculty of Engineering, Benha University, Benha, Egypt \\ "E-mail: mohamed.heikal@fsc.bu.edu.eg
}

Submitted April 1, 2020; accepted May 7, 2020

\begin{abstract}
Keywords: Clay nanoparticles, FA, FBFS, Hydration characteristics, Compressive strength
The present work aims to investigate the influence of clay nanoparticles (CNP) on the mechanical, physical and microstructure cement pastes composites. The cement paste composites were formulated by adding 20-60 mass \% fly ash (FA), fine blast furnace slag (FBFS) and/or 6 mass \% clay nanoparticles. The physico-chemical properties of the cement paste composites $(C P C)$ were improved by the substitution of $6 \% C N P$ in instead of OPC (ordinary Portland cement) in the consistence of the superplasticiser (SP). The physico-mechanical properties and hydration characteristics were investigated by the determination of the setting times (STS), the consistency (W/C, \%), the free lime (FL), the combined water (Wn), the gell space ratio $(X)$, the total porosity (TP), the compressive strength (CS) and the bulk density (BD). The compressive strength values of the cement-CNP hybrid were higher than those of the cement paste composites without CNP. The STs of CPC-pastes containing CNP were accelerated. The CNP showed synergetic effect with the FA and FBFS to enhance the performance of pozzolanic reaction to form supplementary $\mathrm{CSH}, \mathrm{CAH}$ and $\mathrm{CASH}$, these phases are responsible for bridging, producing a rigid closed compact structure; hence the compressive strength, gel/space ratio, bulk density and chemically combined water increased, whereas the porosity decreased.
\end{abstract}

\section{INTRODUCTION}

Nowadays, the construction industry is mainly based on advanced concrete and modified cement paste composites, this is attributed to their, good performance, versatile applications easiness to fabricate, and low expenditure. However, the disadvantages of these cementbased materials, such as their low tensile strength, have led to multiple pathways of degradation in the technical properties of cement-based materials and the high costs of repairing them [1]. Recently, nano-materials were used to enhance all the properties and durability performances of modern concrete. It was shown that adding nanomaterials may enhance the properties due to its surface effect, size effect, and interface effect. Nano-materials (NMs) affect the performance of the physico-mechanical, chemical and microstructure of the cement composite by nucleation, seeding and filler effect. These materials facilitate the pozzolanic reaction to form $\mathrm{C}-\mathrm{S}-\mathrm{H}, \mathrm{CAH}$, and CASH phases within the cementitious matrixes [2-6]. The most commonly used nanomaterials in cementitious products are nanoscale particles like silica-nanoparticles (SNP), $\mathrm{Al}_{2} \mathrm{O}_{3}(\mathrm{NA}), \mathrm{TiO}_{2}(\mathrm{NT}), \mathrm{ZnO}(\mathrm{NZ}), \mathrm{Fe}_{2} \mathrm{O}_{3}(\mathrm{NF})$, clay nanoparticles (CNP) and carbon nano-tubes [7-9].
Clay nanoparticles are inexpensive raw materials that improve the microstructure of the cement composite [10-12]. A feature of CNP is its platelet form having a thickness of $1 \mathrm{~nm}$ and width of 70 to $150 \mathrm{~nm}$. The uses of CNP in concrete may enhance the mechanical properties in cementitious composites by decreasing the porosity and pore size of the cement matrix [13, 14]. It was found that pastes containing 4, 6 and $10 \% \mathrm{CNP}$ showed higher compressive strength values $[15,16]$. It has been postulated that the filling effect of CNP contributes the strength development and the pozzolanic reaction starting within $3-7$ days [17].

The previous study also showed that the $\mathrm{CH}$ content of a cement paste with $10 \%$ CNP decreased up to $42 \%$, this was attributed to the pozzolanicity of CNP, so that CNP improves the texture of the hydration products of the cement pastes and results in a quite dense, compact and uniform microstructure $[15,18]$.

Mineral admixtures such as fly-ash (FA), silica fume (SF) and fine blast furnace slag (FBFS) are waste inorganic materials that have pozzolanic and/or latent hydraulic properties, improve the properties of concrete [19]. The technological and economic benefit use of these waste inorganic materials, as a partial replacement 
in concrete include the improvement of the impermeability, chemical durability, thermal behaviour and enhance the strength. The partial replacement of waste inorganic materials may reduce the early strength, later strength, microstructure and durability of the concrete [20].

Bohá, et al., [21] stated that fine slag offers various technological, economical, and environmental advantages, where it has significantly lower $\mathrm{CO}_{2}$ emissions in comparison with OPC. Subsequently, it is more actively used as an admixture for concrete. Fly ash is also utilised as a by-product of industrial manufacturing processes. Fly ash is the residue from burning coal in power plants, which has glassy spherical particles.

The present research is aimed at studying the effect of clay nanoparticles on the mechanical properties and microstructure of blended cement-pastes.

\section{EXPERIMENTAL}

The starting materials used in this study were OPC, FBFS, FA and clay nanoparticles (CNP). The chemical analyses of these materials were investigated by XRF spectrometry as shown in Table 1 . The clay nanoparticles were calcined at $750{ }^{\circ} \mathrm{C} / 2 \mathrm{hrs}$. The XRD pattern of the raw CNP is shown in Figure 1. The superplasticiserbased polycarboxylate (SP) is an opaque light-yellow liquid with a density of $1.08 \mathrm{~g} \cdot \mathrm{ml}^{-1}$.

The batch composition based on the aforementioned starting materials are tabulated in Table 2. The CNP and SP were stirred with a suitable $\mathrm{W} / \mathrm{C}$ ratio (standard

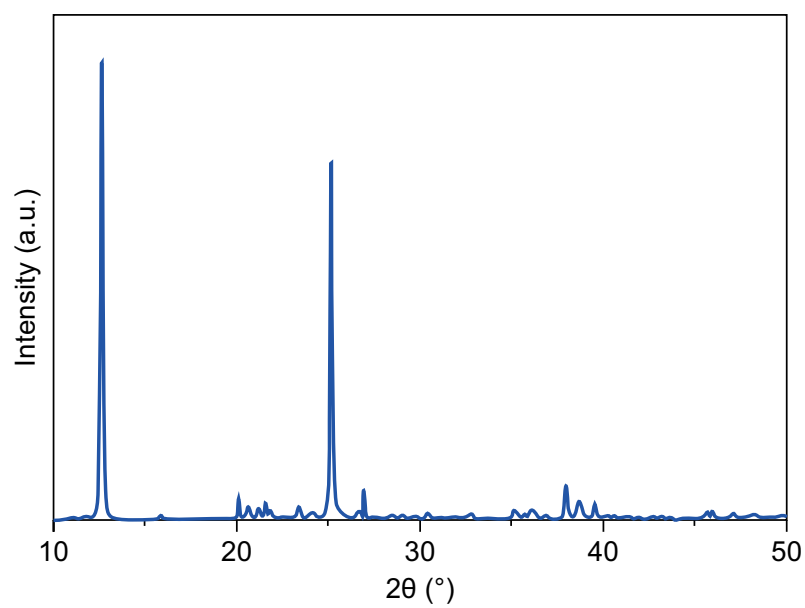

consistency) as given in Table 2, at speed of $120 \mathrm{rpm}$ for two min; the anhydrous blends (OPC, FBFS and/or FA) were mixed to full homogenisation at $90 \mathrm{rpm}$ up to $2 \mathrm{~min}$ and homogenised in a rotary mixer at $120 \mathrm{rpm}$ up to $30 \mathrm{~s}$; then the cement blends were allowed to rest for $90 \mathrm{~s}$; this was followed by mixing at $120 \mathrm{rpm}$ for $1 \mathrm{~min}$, then the blended pastes were cast into $2.5 \times 2.5 \times 2.5 \mathrm{~cm}^{3}$ moulds, and then stored in a humidity cabinet $(100 \% \mathrm{RH})$ at $23 \pm 1{ }^{\circ} \mathrm{C}$ for $24 \mathrm{hrs}$ and then stored under water until the required time of testing (1, 3, 7, 28, 90 and 360-days).

The consistency and STs of the fresh mixed blends were monitored according to ASTM: C191 [22]. The hydrated pastes were stopped using a methanol-acetone mixture, and diethyl ether, and then dried at $70{ }^{\circ} \mathrm{C}$ up to $1 \mathrm{~h}$ [23]. The chemically combined water content (Wn), free lime (FL), bulk density (BD) and total porosity (TP) were determined as described in previous research $[24,25]$. The compressive strength was calculated after the determination of the $\mathrm{BD}$ and $\mathrm{TP}$ according to the ASTM specifications (C-150) [26]. Some selected hydra-ted samples were examined using XRD, DTG/ TGA and SEM techniques to verify the mechanism predicted by the chemical and mechanical tests. For the XRD analysis, a Philips X-ray Diffractometer of $\mathrm{Cu} \mathrm{K} \alpha$ radiation $(\lambda=1.5418 \AA$ ) was used (model PW 1730). The speed of the scan was $2 \theta / \mathrm{min}$ between $5^{\circ}-65^{\circ}$. The X-ray tube voltage was $40 \mathrm{kV}$ and the current was $25 \mathrm{~mA}$. The $\mathrm{XRD}$ analysis was performed with computer software searching for the PDF diffraction data. The TGA/DTG analysis was performed by using a Shimadzu DSC-50 thermal analyser at a heating rate of $10^{\circ} \mathrm{C} \cdot \mathrm{min}^{-1}$, the rate flow of nitrogen was $30 \mathrm{~cm}^{3} \cdot \mathrm{min}^{-1}$. The microstructure of the OPC and some other selected cement pastes were investigated by Scanning Electron Microscope (SEM).

Table 2. The composition of the different mixes (mass \%).

\begin{tabular}{cccccc}
\hline Mix & OPC & FA & FBFS & CNP & SP \\
\hline C0 & 100 & 0 & 0 & 0 & 1 \\
C1 & 94 & 0 & 0 & 6 & 1 \\
C2 & 60 & 40 & 0 & 0 & 1 \\
C3 & 54 & 40 & 0 & 6 & 1 \\
C4 & 60 & 0 & 40 & 0 & 1 \\
C5 & 54 & 0 & 40 & 6 & 1 \\
C6 & 54 & 20 & 20 & 6 & 1 \\
C7 & 34 & 20 & 40 & 6 & 1 \\
\hline
\end{tabular}

Figure 1. The XRD pattern of the raw CNP.

\begin{tabular}{llrlrlrrrrr}
\hline & $\mathrm{SiO}_{2}$ & $\mathrm{Al}_{2} \mathrm{O}_{3}$ & $\mathrm{Fe}_{2} \mathrm{O}_{3}$ & $\mathrm{CaO}$ & $\mathrm{MgO}$ & $\mathrm{SO}_{3}$ & $\mathrm{Na}_{2} \mathrm{O}$ & $\mathrm{K}_{2} \mathrm{O}$ & LOI & Total \\
\hline $\mathrm{CNP}$ & 61.24 & 20.89 & 5.38 & 0.16 & 0.38 & 0.17 & 0.71 & 0.61 & 10.62 & 99.99 \\
FBFS & 43.21 & 9.97 & 0.59 & 35.96 & 5.43 & 1.37 & 0.79 & 0.67 & 1.98 & 99.97 \\
FA & 63.10 & 26.54 & 5.4 & 2.33 & 0.01 & 0.09 & 0.85 & 0.52 & 0.8 & 99.64 \\
OPC & 21.3 & 3.58 & 5.05 & 63.48 & 1.39 & 2.05 & 0.26 & 0.22 & 2.57 & 99.90 \\
\hline
\end{tabular}




\section{RESULTS AND DISCUSSION}

Water consistency, initial, and final setting times

The mixed and design patches of the starting materials are represented in Figure 2. The results show that the CPC pastes containing CNP need excess water for consistency and have shorter setting times when compared with the neat cement paste. The CPC containing CNP was homogenised by a considerable amount of consistency for good workability, in addition to the presence of SP, leading to increases in the fluidity of the fresh CPC; therefore, the $\mathrm{CPC}$ cement pastes possess high hydraulic characteristics, followed by an acceptable setting time when compared with the blank cement paste. This may be due to the acceleration of the ettringite formation and the $\mathrm{CSH}, \mathrm{CAH}$ and $\mathrm{CASH}$ hydrated gel products by the added CNP [27-31].

The results showed that the consistency of CPCpastes containing FBFS are lower than those of the CPC-cement containing the FA-composite. It was found that the FA-composite cement paste containing FA was

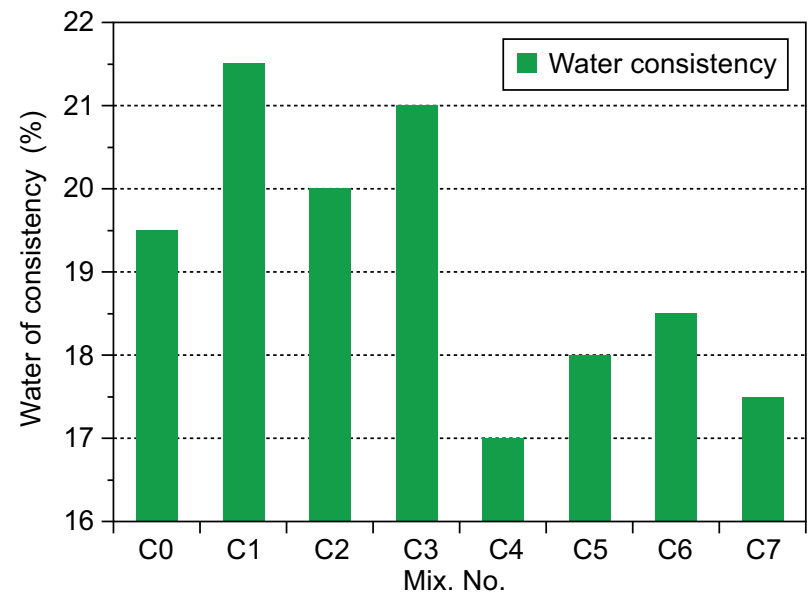

a)

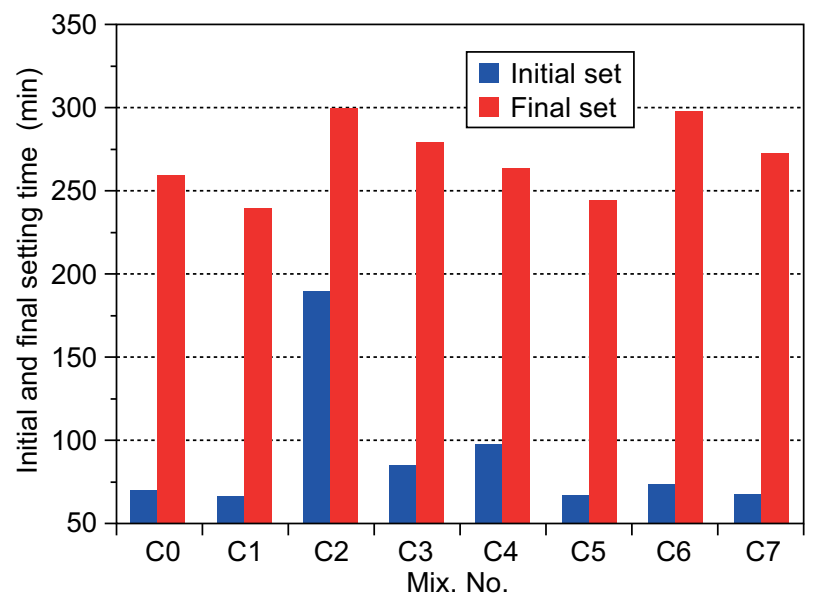

b)

Figure 2. The consistency, setting times of the CPC with and without $6 \% \mathrm{CNP}$. homogenised with a high amount of consistency and gives longer setting times, this is attributed to the lower activity of the FA than the FBFS. On the other hand, the cement containing FBFS showed lower consistency, while the setting times were reduced. It was concluded that mix C5 showed the lowest setting times when compared with all the cement mixes, this may be due to the formation as mentioned before. The STs of the CPC-pastes containing CNP accelerated in the existence of CNP [27]. The results also show that the consistency of mixes $\mathrm{C} 6$ and $\mathrm{C} 7$ decreases, whereas the STs elongated, this is due to the reduction of the OPC-content, as shown in Figure 2.

\section{Free lime contents}

Figures 3 represents the free lime content (FL) of the cement composite pastes containing the CNP after 360 days of curing. From Figure 3, it can be found that all the CPC-pastes mixes showed a decreasing trend, while the blank cement paste (OPC) showed an increasing trend from day 1 up to day 360, respectively. All the CNP mixes cured after 3 days showed a slight decrease in the FL content. For the blank OPC cement paste (mix $\mathrm{C} 1$ ), during all the curing ages of the hydration reaction, it liberates excess $\mathrm{Ca}(\mathrm{OH})_{2}(\mathrm{CH})$ while the addition of $\mathrm{CNP}$ acts as a promotor, which accelerates the pozzolanic reaction which means decreasing the $\mathrm{CH}$ by formation of $\mathrm{CSH}, \mathrm{CAH}$ and $\mathrm{CASH}$ gel hydrates [32, 33]. For the mixes containing FA, FBFS and CNP, which showed a synergetic effect to enhance the pozzolanic reaction performance, leads to a decrease in the free lime contents.

The results show that the FL content of the OPC paste increases with the age up to 360 days, which is attributed to the continued hydration reaction, liberating the $\mathrm{CH}$ through the hydration period. The presence of CNP tends to decrease the residual portlandite, due to the pozzolanic interaction of the CNP with the portlandite leading to the formation of $\mathrm{CSH}, \mathrm{CAH}$ and $\mathrm{CASH}$

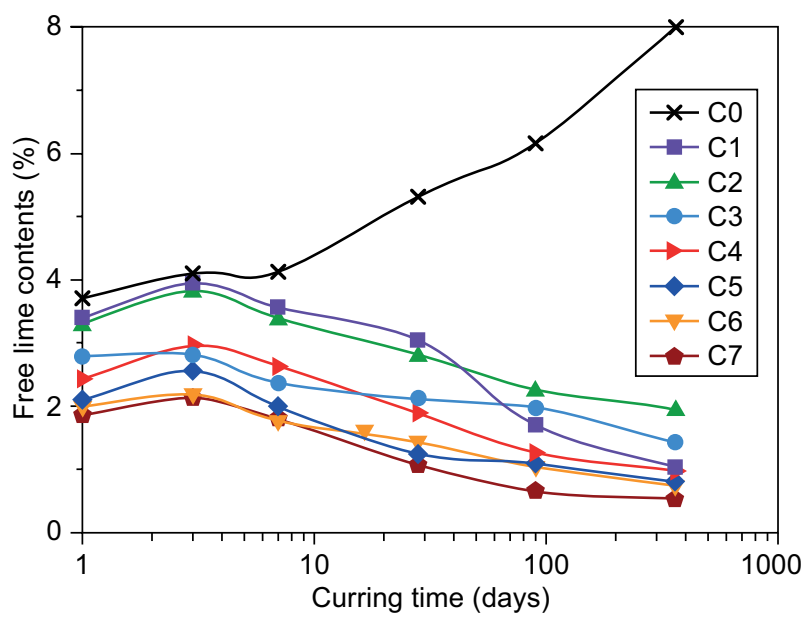

Figure 3. FL of the composite pastes with and without $6 \%$ CNP. 
hydrated gel products [32, 33]. The presence of CNP, leading to the raising of the FL content to 3 days due to the enhances in the hydration reaction OPC (lime production), and then decreases up to 360 days where the rate of consumption of the $\mathrm{CH}$ is higher than the rate of liberation due to higher pozzolanic activity of the CNP (lime consumption). The occurrence of SP tends to approach the CNP particles from the liberated lime to form further $\mathrm{CSH}, \mathrm{CAH}$ and $\mathrm{CASH}$, which precipitated in the vacant pore-system; hence, the porosity decreases as shown later. Mix $\mathrm{C} 7$ showed lower values than mixes $\mathrm{C} 6$ and $\mathrm{C} 5$.

\section{Chemically combined water contents}

The chemically combined water content $\left(W_{n}\right)$ of the different CPC mixes is illustrated in Figure 4. All the mixes showed increasing trends all over the curing ages. The mixes containing 6 mass \% CNP have higher $W_{n}$ values in comparison with the neat-OPC paste. The hydration reaction of the OPC cement phases and the pozzolanic reaction is considered to be the main reason for this increase, the presence of CNP promotes the pozzolanic reaction via the formation of many hydrated phases like $\mathrm{CSH}(\mathrm{I})$ and $\mathrm{CSH}(\mathrm{II})$ with a considerable quantity, which is responsible for increasing the chemically combined water content.

The results show that the pozzolanic action of the FA is lower than that of the FBFS, the FA-compositecement-pastes have lower $W_{n}$ values than the FBFS-CPCcement-pastes. The results also show that the chemically combined water content increases by increasing the content of the FBFS, where mix $\mathrm{C} 7$ has higher $W_{n}$ values than mix $\mathrm{C} 6$, especially at the early ages of hydration, this may due to the pozzolanic reaction of the FBFS, the CNP with the liberated $\mathrm{CH}$ from the OPC cement hydration, which enhances the later hydration times $[34,35]$.

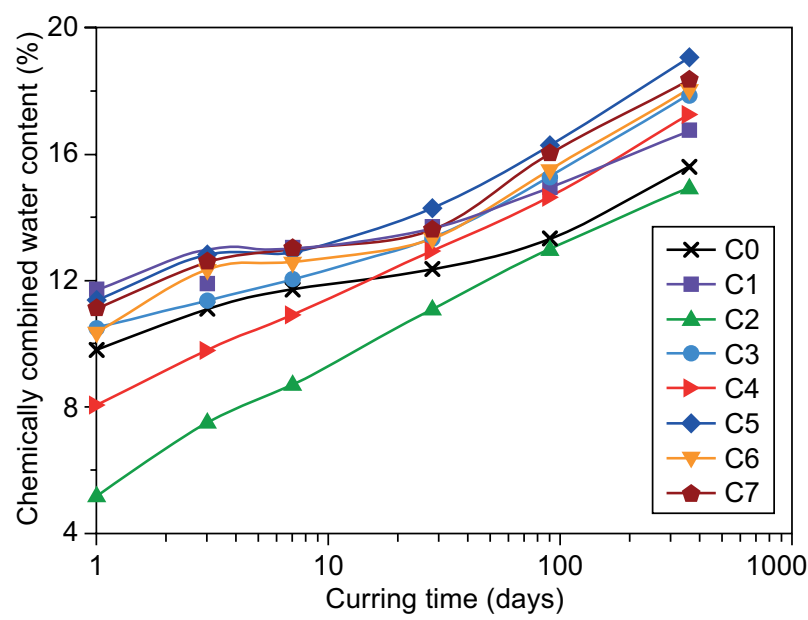

Figure 4. The $\mathrm{Wn}$ of the CPC pastes with and without $6 \%$ CNP.

\section{Compressive strength}

The compressive strength (CS) of the compositepastes containing $6 \% \mathrm{CNP}$ up to 360 -days is illustrated in Figure 5. The data obtained from Figure 5 represent an increase in the CS with an increase in the age-period for all the hardened pastes, qualified to the formation of a successive amount of $\mathrm{CSH}, \mathrm{CAH}$ and $\mathrm{CASH}$ as the main source of strength, these hydrates precipitated in the accessible vacant pores to form a closed compact body [30]. The inclusion of 6 mass \% CNP gives a higher CS than pastes without the CNP (Figure 5), ascribed to the formation of micro- and nano-sized hydrates in the cementitious matrix. The CS of the composite-cementpastes showed better-quality in the presence of $6 \% \mathrm{CNP}$ for all the CPC pastes containing FA and/or FBFS; this is due to the pozzolanic reaction of the CNP and the free $\mathrm{CH}$ liberated during the OPC hydration production [36].

Figure 5 shows that the CS of mix C5 is higher than the FA-CPC pastes (mix $\mathrm{C} 3$ ) this is attributed to the pozzolanic activity of the hybrid CNP and FBFS, which worked to develop the hydration process of the $\mathrm{CPC}$, especially at the later hydration times. The data also, showed that the CS of mix $\mathrm{C} 7$ had higher values than mix C6, due to the pozzolanicity of the FBFS and CNP.

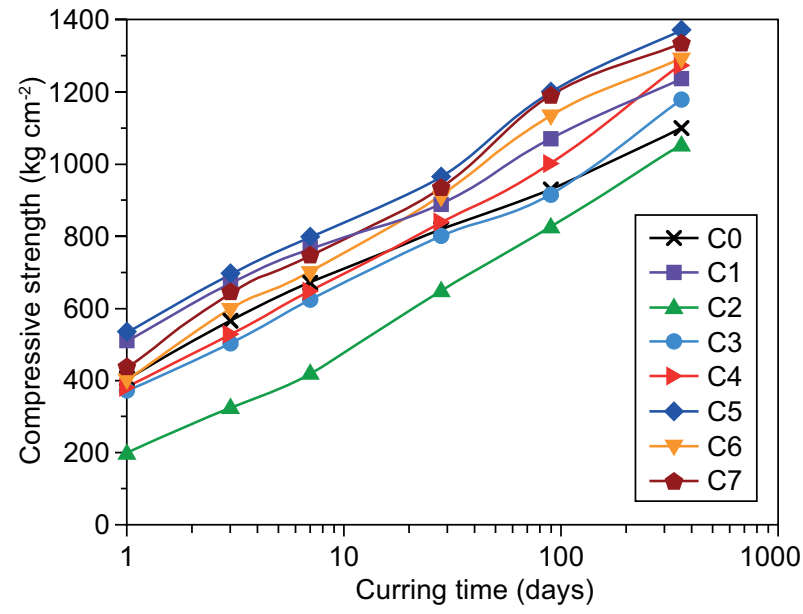

Figure 5. The CS of the composite pastes with and without $6 \% \mathrm{CNP}$.

\section{Gel/space ratio $(X)$}

The gel/space ratio $(X)$ of the CPC-pastes containing FA, FBFS and $6 \% \mathrm{CNP}$ is demonstrated in Figure 6 . The gel/space ratio was influenced by the $\mathrm{W} / \mathrm{C}$ ratio, hydration of degree, porosity, and curingage and temperature. The $X$-ratio increases with the age for all the cement pastes, this is due to the formation of large amounts of CSH, CAH and CASH products [37]. The presence of SP, W/C and TP decrease so that the $X$ values increase [34]. The results showed that mix C5 
show a higher gel/space ratio value in comparison with mix $\mathrm{C} 3$, due to the presence of $6 \% \mathrm{CNP}$, which activates the reaction of the FBFS to give a higher CS and an $X$-ratio as shown in Figures 5 and 6 . The represented results showed that the gel/space ratio increased by the FBFS content (mixes C7 and C6). Mix C7 showed higher gel/space ratio values than $\mathrm{C} 6$, this demonstrates that $40 \%$ of the FBFS is more suitable than $20 \%$ of the FBFS which gives more hydration products.

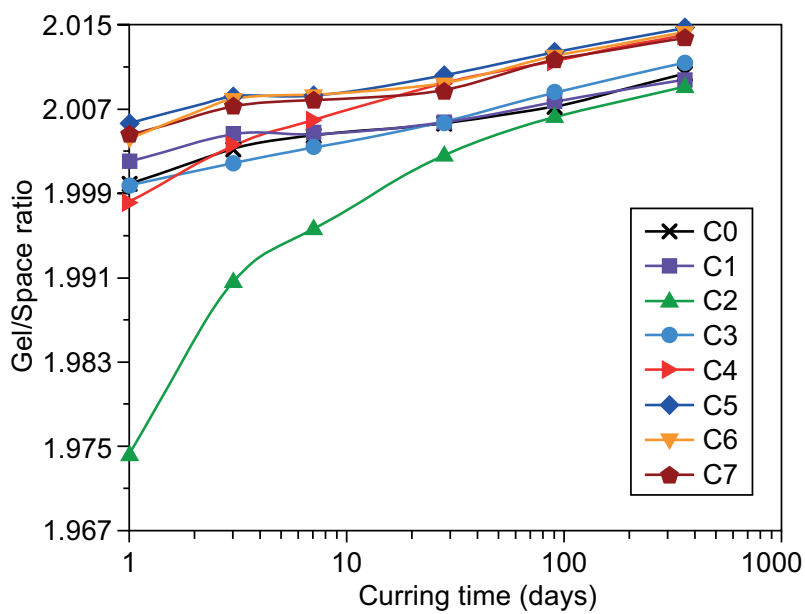

Figure 6 . The gel/space ratio of the pastes containing 6 mass $\%$ CNP.

Bulk density (BD)

and total porosity (TP)

The values of the bulk density (BD) and the total porosity (TP) of the CPC-pastes in the existence of $6 \%$ CNP and the SP in the hybrid effect treated up to 360 days are tabulated in Table 3. The BD increases wherever the TP decreases with the treatment ages, this is accredited to the increases in the excessive hydration products. These products act as binding centres amongst the unhydrated and hydrated phase fractions of the CPC-grains through the progressive hydration, hence the TP decreased. The gel/space ratio and the bulk density increase in addition, the total porosity decreases. The $\mathrm{BD}$ cement composite pastes containing CNP represents higher values than the neat paste and/or the other CPC mixes lacking the CNP [30]. The BD of mix C5 has higher values than those of the neat-paste and mix $\mathrm{C} 3$, especially at later hydration ages. By increasing the content of the FBFS up to $40 \%$, the BD increases and the TP decreases. From the derived results, it can be concluded that the physico-mechanical properties, namely the $\mathrm{CS}$, gel/space ratio, TP, and $\mathrm{BD}$ are in good agreement with each other and they represent an increasing trend, except for the TP, which showed a decreasing trend from 1 day up to 360-days.

\section{XRD patterns}

Figure 7 represents the X-ray diffraction patterns of the hardened $\mathrm{CPC}$ pastes namely the $\mathrm{C} 0, \mathrm{C} 3, \mathrm{C} 5, \mathrm{C} 6$ and $\mathrm{C} 7$ mixes treated at 1 day and 90 days. Figure 7 represents the hydrated and anhydrate-phase diffraction lines of the $\mathrm{CH}, \beta-\mathrm{C}_{2} \mathrm{~S}, \mathrm{C}_{3} \mathrm{~S}, \mathrm{C}, \mathrm{CSH}$ and quartz as shown in Figure. 7. The diffraction lines are consistent to the $\mathrm{C} 0$ mix exhibiting higher intensities as represented for the portlandite diffraction lines.

As the hydration-proceeds, the intensity of the peak, illustrating the diffraction patterns of the $\mathrm{CSH}$, increased, whereas the diffraction patterns corresponding to the $\mathrm{CH}$ decreased from one-day up to 90 days, as represented in the composite pastes containing CNP (mixes C3 and C5). This is due to the pozzolanic reaction between the CNP with the lime liberated during the hydration reaction of the cement, leading to the higher consumption of portlandite and the formation of further $\mathrm{C}-\mathrm{S}-\mathrm{H}$. Increasing the content of the FBFS-FA-CPC pastes, the peaks characteristic to the portlandite and calcite phases decreased; this is due to lowering the content of the OPC.

Table 3. The bulk density and total porosity of the composite pastes in the presence of 6 mass $\% \mathrm{CNP}$.

\begin{tabular}{ccccccccc}
\hline $\begin{array}{c}\text { Time } \\
\text { (days) }\end{array}$ & C0 & C1 & C2 & C3 & C4 density $\left(\mathrm{g} \cdot \mathrm{cm}^{-3}\right)$ & C5 & C6 & C7 \\
\hline & 2.146 & 2.267 & 2.002 & 2.200 & 2.172 & 2.249 & 2.235 & 2.245 \\
1 & 2.178 & 2.301 & 2.074 & 2.239 & 2.181 & 2.275 & 2.251 & 2.266 \\
3 & 2.197 & 2.324 & 2.114 & 2.247 & 2.191 & 2.321 & 2.275 & 2.312 \\
7 & 2.349 & 2.181 & 2.261 & 2.223 & 2.346 & 2.302 & 2.354 \\
28 & 2.226 & 2.205 & 2.273 & 2.267 & 2.384 & 2.341 & 2.381 \\
90 & 2.252 & 2.367 & 2.232 & 2.299 & 2.311 & 2.421 & 2.379 & 2.401 \\
360 & 2.288 & 2.410 & & Total porosity (\%) & & & \\
\hline \hline Time & & & & C3 & C4 & C5 & C6 & C7 \\
(days) & C0 & C1 & C2 & 32.21 & 29.43 & 28.16 & 29.07 & 29.60 \\
\hline 1 & 31.24 & 28.45 & 32.24 & 29.31 & 28.39 & 27.83 & 28.67 & 29.00 \\
3 & 30.01 & 27.96 & 31.76 & 29.31 & 26.62 & 27.06 & 28.10 \\
7 & 29.21 & 26.93 & 30.96 & 28.19 & 27.19 & 25.75 & 26.21 & 27.30 \\
28 & 28.65 & 25.94 & 29.45 & 27.43 & 25.75 & 24.11 & 24.79 & 26.10 \\
90 & 27.11 & 24.60 & 28.04 & 26.22 & 24.01 & 22.48 & 23.10 & 24.30 \\
360 & 25.47 & 23.08 & 26.14 & 24.46 & 22.69 & & \\
\hline
\end{tabular}


This result is in good agreement with the results of the compressive strength and the gel/space ratio.

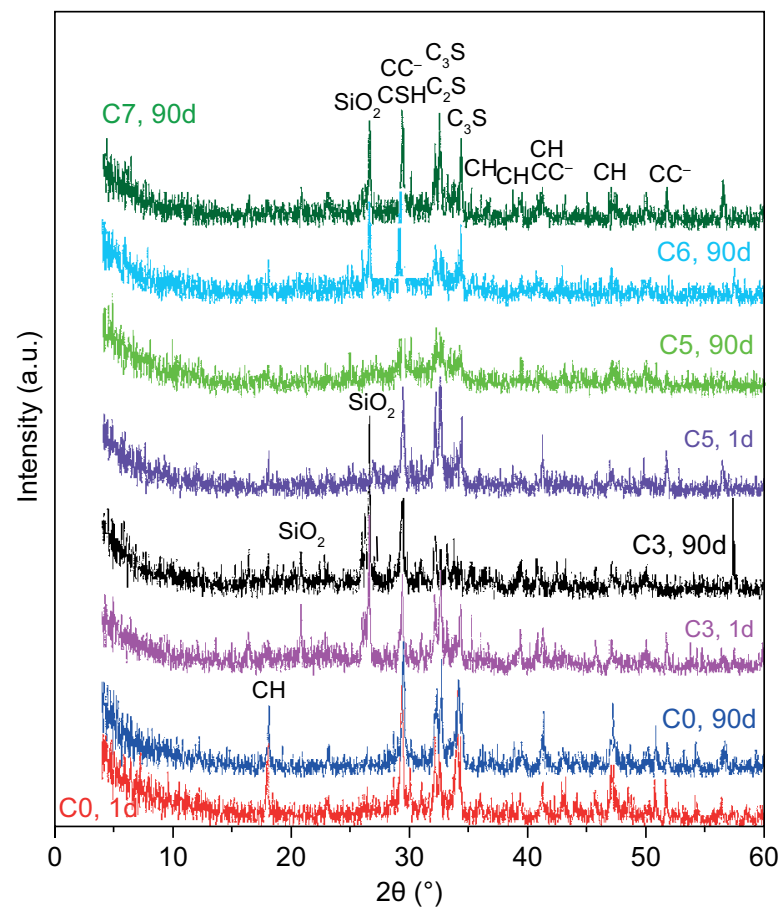

Figure 7. The XRD patterns of the CPC-pastes cured at 1 day, 90 days.

\section{TGA/DTG thermograms}

The TGA/DTG thermograms of the OPC and composite pastes containing $6 \% \mathrm{CNP}$ and $1 \% \mathrm{SP}$ cured at 1 day and 90 days are represented in Figure 8. The DTG/TGA curves show the typical temperature events up to $1000{ }^{\circ} \mathrm{C}$. The peaks presented at $80-190$ ${ }^{\circ} \mathrm{C}$ are attributed to the decomposition of the calcium silicate hydrate, tri-sulphoaluminate hydrate (AFt), and/ or monosulphate-hydated products (AFm). The peak situated at $120-190{ }^{\circ} \mathrm{C}$ is related to the dehydration of the $\mathrm{CSH}$ in the different crystalline states, which overlapped with the Aft, AFm and CASH hydrates [38]. However, the peak situated at $450-525^{\circ} \mathrm{C}$ is interrelated to the dehydroxylation of $\mathrm{CH}[39,40]$. The endothermic peaks detected at 680 and $720{ }^{\circ} \mathrm{C}$ are accredited to the calcination of the amorphous and crystalline $\mathrm{CaCO}_{3}(\mathrm{C})$ [41]. The exothermic peak located at $850-950{ }^{\circ} \mathrm{C}$ is due to the recrystallisation of the monocalcium silicate, which is produced from the pozzolanic reaction [42]. Figure 8A illustrates the TGA/DTG thermograms of the C0 mix hydrated for 1 day and 90 days, it can be deduced that the areas under the peaks corresponding to the $\mathrm{C}-\mathrm{S}-\mathrm{H}$ and $\mathrm{CH}$ phases increase with the treatment ages. Whereas the addition of CNP to the FA and/or FBFS CPC-paste leads to an increase in the area under the peak identical to $\mathrm{CSH}$ and used up the $\mathrm{CH}$ in its pozzolanic action, hereafter, the area under the peak identical to the $\mathrm{CH}$ decreases when compared with the neat paste as shown in Figure $8 \mathrm{~B}$ and $8 \mathrm{C}$.

\section{Microstructure and morphology of cement paste composites}

The SEM micrographs of the selected cement com-posite mixes $\mathrm{C} 3, \mathrm{C} 5, \mathrm{C} 6$, and $\mathrm{C} 7$ are represented in Figure 9a-e. From Figure 9a-e, it was found that the sample C3 cured after 90 days of hydration showed

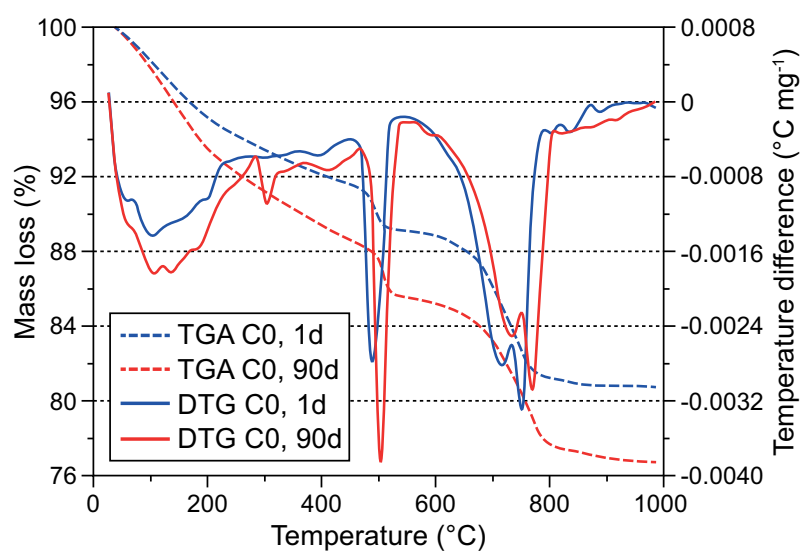

a)

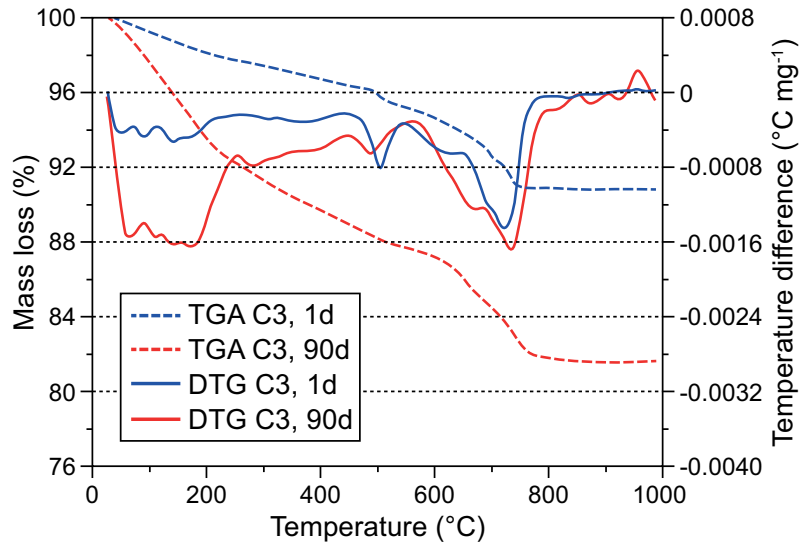

b)

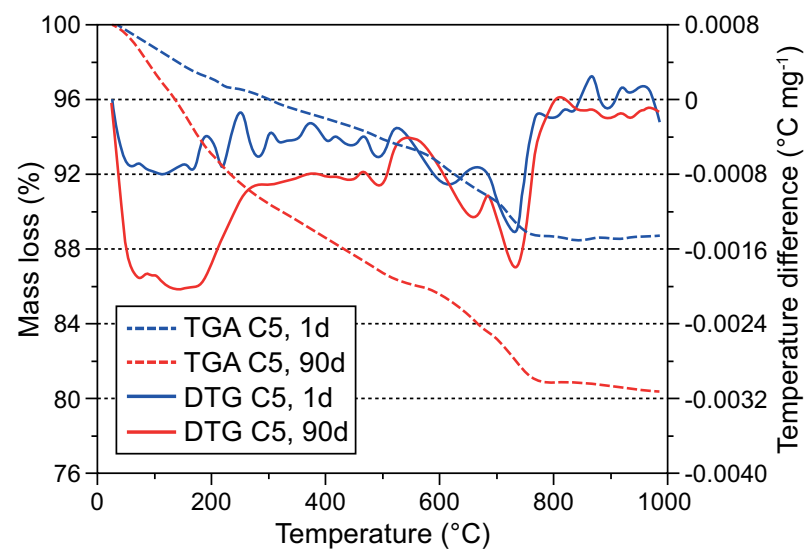

c)

Figure 8 . The consistency, setting times of the CPC with and without $6 \%$ CNP. 


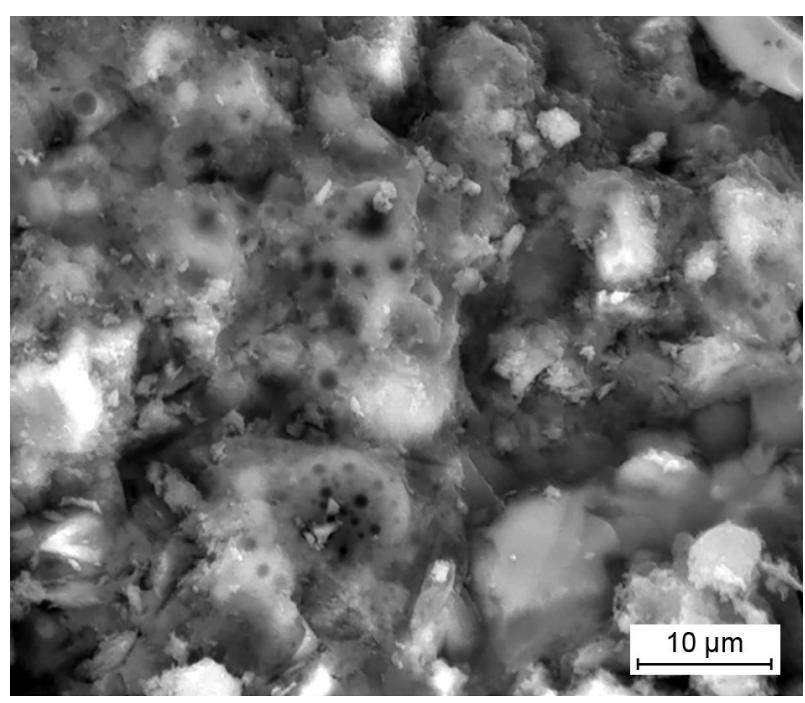

a)

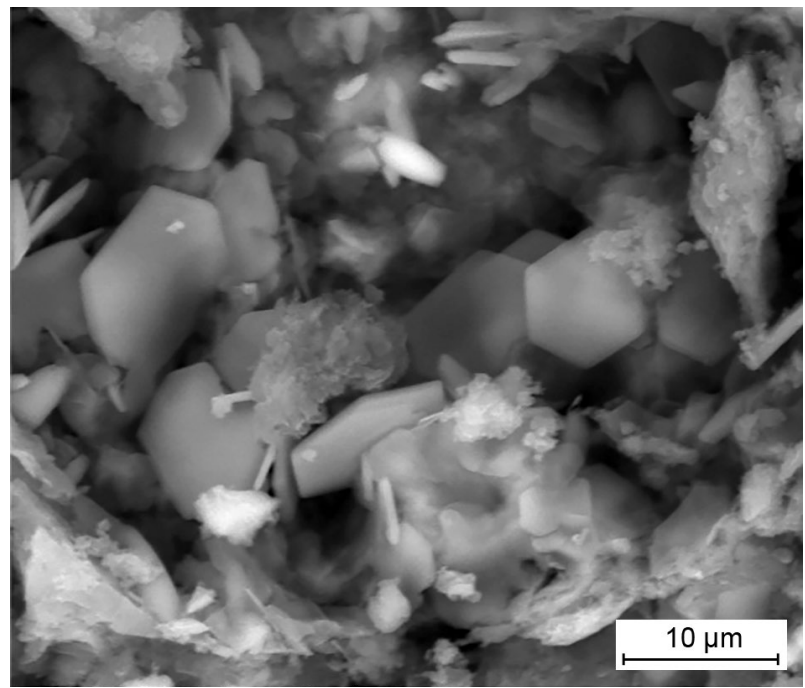

b)

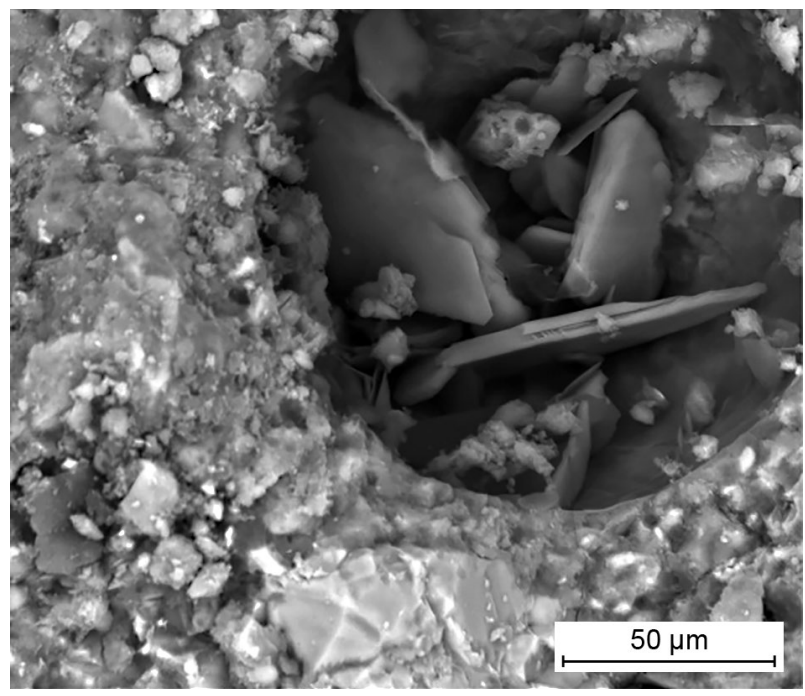

c)

a denser structure, which is mainly composed of the fully nano-crystalline hydration products and rod like particles of the CSH (Figure 9a). The dense structure may be due to the effect of the CNP particles' nucleus, which accelerates the pozzolanic activity leading it to form a homogenous compact CPC.

The SEM micrograph of mix $\mathrm{C} 5$ treated after 90 days depicts a porous microstructure with wider pores available for the crystallisation of the formed $\mathrm{CSH}, \mathrm{CAH}, \mathrm{CASH}$. These microstructures exhibit a higher degree of crystallinity of a mineral hexagonal form of gehlenite like hydrate $\left(\mathrm{C}_{2} \mathrm{ASH}_{8}\right)$, the pore size decreases due to the higher activity of the CNP as shown in Figure 9b. This microstructure reflects the higher compressive strength values, which promotes a decrease in the free lime by the formation of the $\mathrm{CSH}, \mathrm{CAH}, \mathrm{CASH}$ phases [43-45].

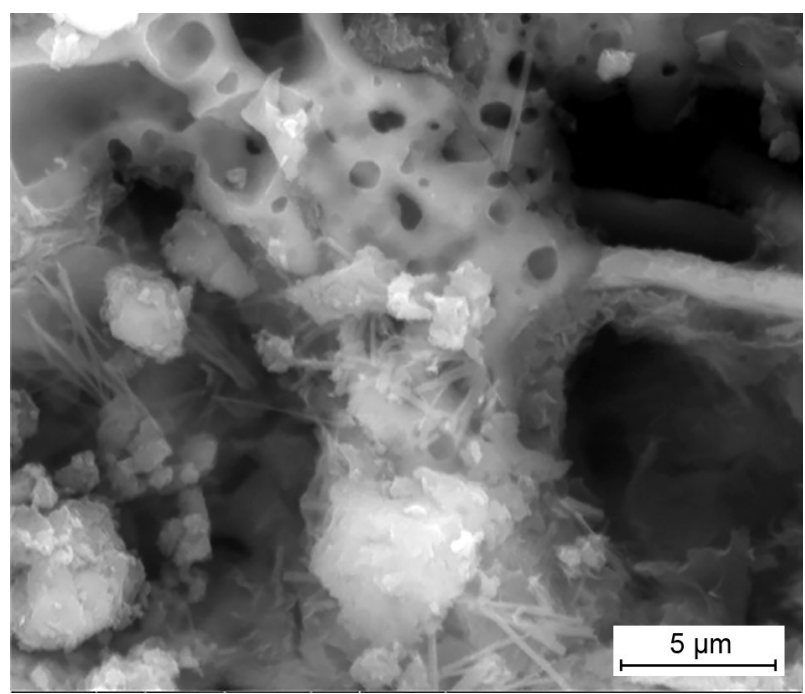

d)

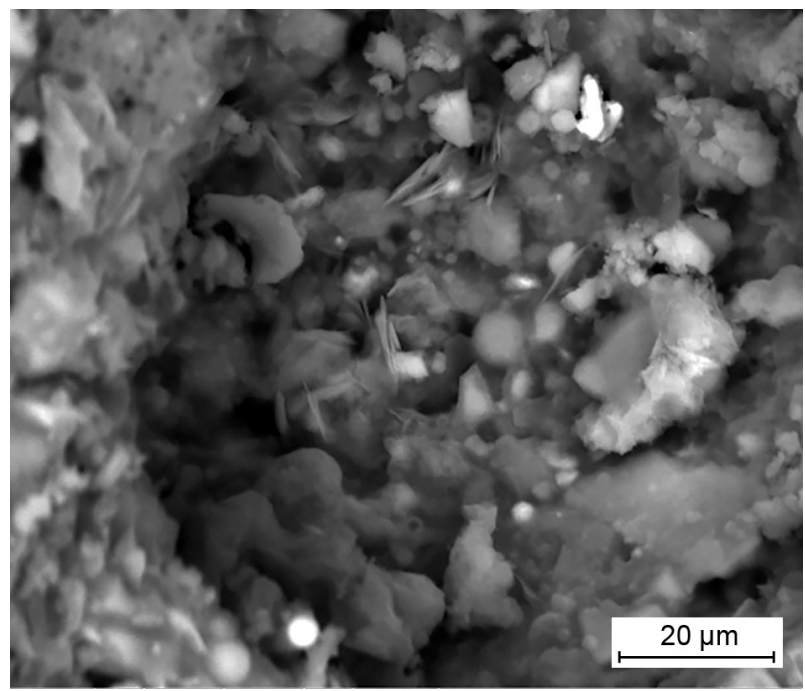

e)

Figure 9. The SEM micrographs of the composite cement pastes; a) C3-90d; b) C5-90d; c) C6-90d with 50 $\mu$ magnification; d) C6-90d with $10 \mu \mathrm{m}$ magnification; e) C7-90d. 
Figure $9 \mathrm{c}$ and $9 \mathrm{~d}$ represent the micrographs of the hardened cement paste composite C6 with different magnifications treated at 90 days. The SEM micrograph of mix $\mathrm{C} 6$ displayed the presence of $\mathrm{C}-\mathrm{S}-\mathrm{H}$ and $\mathrm{CH}$ as the main hydrated products in addition to the presence of $\mathrm{C}-\mathrm{A}-\mathrm{H}, \mathrm{C}_{2} \mathrm{ASH}_{8}$ and $\mathrm{C}_{3} \mathrm{AH}_{8}$. The microstructure of mix $\mathrm{C} 6$ is a heterogeneous structure where it contains different types and number of pores when compared with mix $\mathrm{C} 5$. This microstructure reflects the variation of both the compressive strength, bulk density and porosity.

Figure 9e represents the micrograph of $\mathrm{C} 7$, the microstructure represents the flaky plate-like morphology of $\mathrm{C}_{2} \mathrm{ASH}_{8}$. It also shows the presence of ill-crystalline and microcrystalline hydrates of $\mathrm{C}-\mathrm{S}-\mathrm{H}$ with the complete disappearance of $\mathrm{Ca}(\mathrm{OH})_{2}$. After 90 days of hydration, more hydrated products were placed in the pores where the denser structure is obtained. The micrograph also shows longer rod-like formations of $\mathrm{C}-\mathrm{S}-\mathrm{H}$. This $\mathrm{CSH}$ phase is in a large quantity, which is responsible for bridging the cement particles, producing a rigid closed compact structure.

\section{CONCLUSIONS}

It can be concluded that:

- The results show that the CPC pastes containing CNP need excess water for consistency and shorter setting times when compared with the neat cement paste. The STs of the CPC-pastes containing CNP accelerated in the existence of the CNP. The results also show that the consistency of mixes C6 and C7 decreased, whereas the STs elongated.

- The free lime content of the CPC-pastes mixes showed a decreasing trend, while the OPC showed increasing trends from 1 day up to 360 days. The mixes containing CNP showed a synergetic effect with the FA and the FBFS to enhance the pozzolanic reaction performance forming further $\mathrm{CSH}, \mathrm{CAH}$ and $\mathrm{CASH}$, which precipitated in the vacant pore-system producing a compact matrix; hence, the compressive strength, gel/ space ratio, bulk density and chemically combined water increased, whereas the porosity decreased.

- The microstructure of the $\mathrm{CPC}$ represented the presence of the flaky plate-like morphology of $\mathrm{C}_{2} \mathrm{ASH}_{8}$ as well as the ill-crystalline and microcrystalline hydrates of $\mathrm{C}-\mathrm{S}-\mathrm{H}$ with the complete disappearance of $\mathrm{Ca}(\mathrm{OH})_{2}$. This $\mathrm{CSH}$ phase is responsible for bridging, producing a rigid closed compact structure.

\section{REFERENCES}

1. Yang H., Cui H., Tang W., Li Z., Han N., Xing F. (2017): A critical review on research progress of graphene/cement based composites. Composites Part A: Applied Science and Manufacturing, 102, 273-296. doi: 10.1016/j.compositesa. 2017.07.019
2. Nik A.S., Bahari A. (2012): Nano-particles in concrete and cement mixtures. Applied Mechanics and Materials, 110, 3853-3855. doi: 10.4028/www.scientific.net/AMM. $110-116.3853$

3. Norhasri M.S.M., Hamidah M.S., Fadzil A.M. (2017): Applications of using nano material in concrete: A review. Construction and Building Material, 133, 91-97. doi: 10.1016/j.conbuildmat.2016.12.005

4. Amin M. S., Abo-El-Enein S. A., Abdel Rahman A., Alfalous K. A. (2012): Artificial pozzolanic cement pastes containing burnt clay with and without silica fume: physicochemical, microstructural and thermal characteristics. Journal of Thermal Analysis and Calorimetry, 107(3), 1105-1115. doi: 10.1007/s10973-011-1676-5

5. Montes O.B., Palacios M., Rivilla P., Puertas F. (2012): Compatibility between superplasticizer admixtures and cements with mineral additions. Construction and Building Material, 31, 300-309. doi: 10.1016/j.conbuildmat.2011. 12.092

6. Aye T., Oguchi C.T. (2011): Resistance of plain and blended cement mortars exposed to severe sulfate attacks. Construction and Building Material, 25, 2988-2996. doi: 10.1016/j.conbuildmat.2010.11.106

7. Han B., Sun S., Ding S., Zhang L., Yu X., Ou J. (2015): Review of nanocarbon-engineered multifunctional cementitious composites. Composites Part A: Applied Science and Manufacturing, 70, 69-81. doi: 10.1016/j.compositesa. 2014.12.002

8. Mukhopadhyay A. K. (2011). Next-generation nano-based concrete construction products: a review. In Nanotechnology in Civil Infrastructure. Springer, Berlin, Heidelberg, pp. 207-223. doi: 10.1007/978-3-642-16657-0_7

9. Shah S. P., Hou P., Konsta-Gdoutos M. S. (2016): Nanomodification of cementitious material: Toward a stronger and durable concrete. Journal of Sustainable Cement-Based Materials, 5(1-2), 1-22. doi: 10.1080/21650373.2015. 1086286

10. Hakamy A., Shaikh F. U. A., Low I. M. (2015).: Characteristics of nanoclay and calcined nanoclay-cement nanocomposites. Composites Part B: Engineering, 78, 174-184. doi: 10.1016/j.compositesb.2015.03.074

11. Aly M., Hashmi M. S. J., Olabi A. G., Messeiry M., Hussain A. I. (2011): Effect of nano clay particles on mechanical, thermal and physical behaviours of waste glass cement mortars. Material and Science Engineer, 528, 7991-7998. doi: 10.1016/j.msea.2011.07.058

12. Alamri H., Low I. M., Alothman Z. (2012): Mechanical, thermal and microstructural characteristics of cellulose fibre reinforced epoxy/organoclay nanocomposites. Composites Part B: Engineering, 43(7), 2762-2771. doi: 10.1016/j. compositesb.2012.04.037

13. Wei J., Meyer C. (2014): Sisal fiber-reinforced cement composite with Portland cement substitution by a combination of metakaolin and nano-clay, Journal of Material Science, 49, 7604-7619. Doi: 10.1007/s10853-014-8469-8

14. Taha S. (2010): Thermo-Mechanical Properties of Activated Nano Clay Cement Pastes at Different Curing Temperatures. In: International Conference on Nano Technology for Green and Sustainable Construction, Cairo, pp. 14-17.

15. Morsy M. S., Alsayed S. H., Aqel, M. (2010): Effect of nano-clay on mechanical properties and microstructure of ordinary Portland cement mortar. International Journal of Civil \& Environmental Engineering IJCEE-IJENS, 10(01), 23-27. 
16. Supit S. W. M., Rumbayan R., Ticoalu A. (2017): Mechanical properties of cement concrete composites containing nano-metakaolin. AIP Conference Proceedings, 1903, 050001. doi: 10.1063/1.5011540

17. Norhasri M. M., Hamidah M. S., Fadzil A. M., Megawati O. (2016): Inclusion of nano metakaolin as additive in ultra high performance concrete (UHPC). Construction and Building Materials, 127, 167-175. doi: 10.1016/j. conbuildmat.2016.09.127

18. Shoukry H., Kotkata M. F., Abo-el-Enein S. A., Morsy M. S. (2013): Flexural strength and physical properties of fiber reinforced nano metakaolin cementitious surface compound. Construction and Building Materials, 43, 453-460. doi: 10.1016/j.conbuildmat.2013.02.030

19. Kosmatka S.H., Panarese W.C. (1988). Design and Control of Concrete Mixtures. Skokie, IL, USA,Portland Cement Association, p. 17, 42, 70, 184.

20. Shi C., Qian J. (2000): High performance cementing materials from industrial slag. Resources, Conservation and Recycling, 29, 195-220. doi: 10.1016/S0921-3449(99) 00060-9

21. Boháč M., Palou M., Novotný R., Másilko J., Všianský D., Staněk T. (2014): Investigation on early hydration of ternary Portland cement-blast-furnace slag - Metakaolin blends. Construction and Building Materials, 64, 333-341. doi: 10.1016/j.conbuildmat.2014.04.018

22. ASTM C191 (2008). Standard method for normal consistency and setting of hydraulic cement.

23. Abd-El Aziz M.A., Heikal M., Abd El Aleem S. (2012): Physico-chemical and mechanical characteristics of pozzolanic cement pastes and mortars hydrated at different curing temperatures. Construction and Building Material, 26, 310-316. doi: 10.1016/j.conbuildmat.2011.06.026

24. Abd-El-Eziz M.A., Heikal M. (2009): Hydration characteristics and durability of cements containing fly ash and limestone subjected to Qaron's Lake Water. Advanced Cement Research, 21,91-99. doi: 10.1680/adcr.2007.00025

25. El-Didamony H., Abd-El Eziz M., Abd El Aleem S., Heikal M. (2005): Hydration and durability of sulfate resisting and slag cement blends in Qaron's Lake water. Cement and Concrete Research, 35, 1592-1600. doi: 10.1016/j. cemconres.2004.06.038

26. ASTM C109 (2007). Strength test method for compressive strength of hydraulic cement mortars.

27. Badogiannis E., Kakali G., Tsivilis S. (2005): Metakaolin as supplementary cementitious material: optimization of kaolin to metakaolin conversion. Journal of Thermal Analysis and Calorimetry, 81(2), 457-462. doi: 10.1007/ s10973-005-0806-3

28. Sololev K., Nemecek J., Smilauer V., Zeman, J. (2009): Engineering of nano particals for optimal performance in nano cement based materials. In: Nanotechnology in Constr. Proc., Prague, pp. 139-148.

29. Li G. (2004): Properties of high volume of Fly ash concrete incorporating nano- $\mathrm{SiO}_{2}$. Cement and Concrete Research, 34, 1043-1049. doi: 10.1016/j.cemconres.2003.11.013

30. Nazari A., Riahi S. (2011): The effects of $\mathrm{SiO}_{2}$ nanoparticles on physical and mechanical properties of high strength compacting concrete. Composites Part B: Engineering, 42(3), 570-578. doi: 10.1016/j.compositesb.2010.09.025
31. Heikal M., Aiad I., Shoaib M.M., EL-Didamony H. (2001): Physico-chemical characteristics of some polymer cement composites. Materials Chemistry and Physics, 71, 76-83. doi: 10.1016/S0254-0584(01)00346-7

32. Esteves L.P. (2011): On the hydration of water-entrained cement-silica system combined SEM, XRD and thermal analysis in cement pastes. Thermochimica Acta, 518, 27-35. doi: 10.1016/j.tca.2011.02.003

33. El-Diadamony H., Amer A. A., Sokkary T. M., El-Hoseny S. (2018): Hydration and characteristics of metakaolin pozzolanic cement pastes. HBRC Journal, 14(2), 150-158. doi: 10.1016/j.hbrcj.2015.05.005

34. Khatib J.M., Hibbert J.J. (2005): Selected engineering properties of concrete incorporating slag and metakaoline. Construction and Building Material, 19, 460-472. doi: 10.1016/j.conbuildmat.2004.07.017

35. Deschner F., Winnefeld F., Lothenbach B., Seufert S., Schwesig P., Dittrich S., Goetz-Neunhoeffer F., Neubauer J. (2012): Hydration of Portland cement with high replacement by siliceous fly ash. Cement and Concrete Research, 42, 1389-1400. doi: 10.1016/j.cemconres.2012.06.009

36. Echart A., Ludwig H.M., Stark J. (1995): Hydration of the four main Portland cement clinker phases. Zemenk-KalkGips, 28, 443-452.

37. Abd El-Aziz M., Abd El-Aleem S., Heikal M., El-Didamony H. (2004): Effect of Polycarboxylate on Rice Husk Ash Pozzolanic Cement. Sil. Ind. 69, 73-84.

38. El-Didamony H.,AmerA.A.,Helmy I.M., Mostafa K. (1996): Durability of sulphate resisting slag blended cements and mortars in sea water. Indian Journal of Engineering and Materials Sciences (IJEMS), 3, 35-40.

39. Esteves L.P. (2011): On the hydration of water-entrained cement-silica systems combined SEM, XRD and thermal analysis in cement pastes. Thermochimica Acta, 518, 27-35. doi: 10.1016/j.tca.2011.02.003

40. Wongkeo W., Chaipanich A. (2010): Compressive strength, microstructure and thermal analysis of autoclaved and air cured structural lightweight concrete made with coal bottom ash and silica fume. Material Science Engineering, 527, 3676-3684. doi: 10.1016/j.msea.2010.01.089

41. Vedalakshmi R. (2003): Quantification of hydrated cement products of blended cement in low and medium strength concrete using TG and DTG technique. Thermochimica Acta, 407, 49-60. doi: 10.1016/S0040-6031(03)00286-7

42. Ramachandran V.S. (2001). Thermal Analysis. In: Handbook of analytical techniques in concrete science and technology. Noyes publications, New Jersey.

43. Colston S.L., Connor D., Barnesm P. (2000): Functional micro-concrete: The incorporation of zeolites and inorganic nano-particles into cement micro-structures. Journal of Materials Science Letters, 19, 1085-1088.

44. Lia K., Chang P., Peng Y., Yang C. (2004): Study on characteristics of interfacial transition zone in concrete. Cement and Concrete Research, 34, 977-989. doi: 10.1016/ j.cemconres.2003.11.019

45. Al-Salami A.S., Taha S., Shoukry H. (2013): Physicomechanical characteristics of blended white cement pastes containing thermally activated ultrafine nano-clays. Construction and Building Materials, 47, 138-145. doi: 10.1016/j.conbuildmat.2013.05.011 